\title{
Determination of Snow Water Equivalent for Dry Snowpacks using the Multipath Propagation of Ground-based Radars
}

\author{
Pedro F. Espín-López, Member, IEEE, and Marco Pasian, Senior Member, IEEE
}

\begin{abstract}
Determining snow water equivalent (SWE) in a fast and non-destructive way is a key request for many hydrologists and snow scientists. To this aim, microwave ground-based radars represent a viable solution, but often the simultaneous measurement of both the snowpack depth and density (the key ingredients for the SWE) is very complex, inaccurate, or requires difficult procedures and equipment.

This paper presents a novel radar technique for self-standing calculation of the SWE that can be applied to bi-static radars. This technique, based on the multipath propagation of the radar signal into the snowpack, only require a radar with two fixed antennas, without any other device, movement of the antennas, or a-priori empirical assumptions. This makes such a technique particularly suitable for light and portable radars for rapidly probing large areas, providing for example an innovative validation means for satellite-based microwave remote sensing methods. The proposed technique was demonstrated using a stepped frequency modulated continuous wave (FMCW) radar in field conditions for dry snow, delivering results for snow depth and SWE, benchmarked by manual analyses of the snowpack, with a mean absolute error better than $5 \mathrm{~cm}$.
\end{abstract}

Index Terms-FMCW microwave ground-based bi-static radar, multipath, snowpack monitoring, snow water equivalent (SWE).

\section{INTRODUCTION}

SNOW WATER EQUIVALENT (SWE) is an important $S_{\text {parameter describing the amount of liquid water potentially }}$ related to the snowpack. SWE can be calculated as:

$$
\mathrm{SWE}=D \rho / \rho_{\mathrm{W}}
$$

where $D$ is the snowpack depth, $\rho$ is the snow density, and $\rho_{\mathrm{w}}$ is the water density $\left(1000 \mathrm{~kg} / \mathrm{m}^{3}\right)$. This information is useful in several applications, including climate modelling and water management for hydroelectric power plants and agriculture [1, 2]. A number of approaches, based on ground-based in-situ monitoring $[3,4]$ and/or space-based remote sensing (e.g., using the signal from global navigation satellite systems [5],

This work was supported by the Italian Ministry of Education, University and Scientific Research (MIUR), under the project SIR2014 "SNOWAVE" RBSI148WE5, and by the European Union (EU) H2020 INTERACT Transnational Access project "ARCTICWAVE".

P. F. Espín-López was with the Dept. of Electrical, Computer and Biomedical Engineering, University of Pavia, Pavia, Italy (e-mail:
[6], passive microwave radiometers [7], [8], active [9]-[13], and signal-of-opportunity radars [14]), are proposed to monitor the snowpack, possibly deriving the SWE, over large areas.

However, over large and remote areas, for example an entire mountain basin, in situ monitoring is complex, costly, and difficult to be run, especially over difficult ground (e.g., steep slopes). At the same time, satellite remote sensing may not provide the required spatial and/or temporal resolution, especially on complex terrain (e.g., mountains) [15]-[17].

For these reasons, the availability of portable, fast-deploying devices able to measure the SWE at several different locations, at arbitrary repetition rates, over large areas, is interesting. In addition, they would be valuable also for calibrating/validating satellite-based measurements. To this aim, ground-based microwave radars represent an effective solution, due to the nature of the measurement, which is practically instantaneous and non-destructive. However, for measuring the SWE, the radar needs to determine both the snow depth and the snow density. Unfortunately, this is an ill-posed problem, as the snow depth can be calculated from the time-of-flight of the radar signal only if the wave speed is known, but the latter is driven by the snow density, which is unknown in the general case.

To solve this problem different techniques are employed. These include: i) a-priori hypothesis on the snow density; ii) the use of additional devices measuring either the snowpack depth or density; iii) approaches derived from ground penetrating radars (GPRs), for example based on the best fitting of the diffraction curve (common offset, common mid-point) or on the migration analysis [18-26]. However, these techniques have their own flaws. For example: i) a-priori assumptions can lead to large errors; ii) additional devices increase the system complexity, and in many cases are not suited for portable systems; iii) GPR-based techniques require fortuitously located diffractors, antenna displacement strategies or mechanisms, and/or are potentially prone to inaccuracies typical of inverse techniques, such as local minima, artefacts, and computation time and effort [27].

An alternative to these techniques is represented by a different radar architecture, sketched in Fig. 1a, which makes

pedrofidel.espinlopez01@universitadipavia.it). Now, he is with the Geomatics Division, Centre Tecnològic de Telecomunicacions de Catalunya (CTTC), Castelldefels, Spain. M. Pasian is with the Dept. of Electrical, Computer and Biomedical Engineering, University of Pavia, Pavia, Italy (e-mail: marco.pasian@unipv.it.). 
use of two different receivers, recently presented in [28]. In this case, two independent propagation paths (thus, two independent measurements for the time of flight), from the transmitter (tx) to the first and second receiver ( $\mathrm{rx} 1$ and $\mathrm{rx} 2$, respectively), are available to provide two independent equations. This way, the two unknowns, i.e., the snowpack depth $D$ and the wave speed $v$ into the medium can be determined, thus closing rigorously the mathematical problem. However, this architecture works with three antennas, which require precision during the reciprocal alignment. In view of a portable solution, where the radar is most likely transported partially dismounted, and assembled in situ, this is a delicate procedure.

This paper presents an innovative solution for ground-based microwave radars aimed at snowpack monitoring. Following the idea of using two different receivers, these are virtually realized exploiting the multipath propagation between the airsnow and the snow-ground interface. This means that the radar system only comprises two, instead of three, antennas, greatly reducing the overall encumbrance and alignment aspects, thus improving the portability and the easiness and rapidity of deployment. This idea, which is particularly suited for monitoring the SWE over large areas, is experimentally verified for dry snow during field campaigns in 2019 in the Italian Alps and in Lapland. This paper is organized as follows. Section II describes the architecture of the adopted approach and the underlying equations, while Section III presents the practical implementation, along with the experimental results. Section IV draws the conclusions.

\section{MUlTiPATH RADAR ARCHITECTURE}

Starting from the working principle presented in [28], and briefly summarized at the end of Sec. I, here, the second tx-rx pair is replaced by taking advantage of the multipath propagation in the first tx-rx pair, in most cases a non-desirable effect. This is, in the ideal case of a homogeneous snowpack, the shorter wave path between the transmitter and the receiver will bounce only once in the snow-ground interface. Moreover, there will be a longer wave, which can be called second path, bouncing twice in the snow-ground interface and once in the air-snow interface (Fig. 1b). For completeness, the extension of this same idea would bring to the identification of multiple longer wave paths, bouncing multiple times both in the snowground and in the air-snow interfaces, thus creating multiple targets placed at a well-known distance depending on the geometry of the problem. It is worth noting that the hypothesis of a homogeneous snowpack does not introduce a limitation, as real stratified snowpacks, for what concerns applications related to the SWE, can be in most of the cases traced back to their average, homogeneous, equivalent snowpacks.

These multipath targets usually represent a non-desirable effect on radar applications. However, for the case under analysis, if at least the first multipath target could be detected, the two different wave paths would close the mathematical problem rigorously. In particular, the time-of-flight $T_{1}$ and $T_{2}$ associated to the first and second path is, respectively:

$$
\begin{aligned}
& T_{1}=d_{1} / v \\
& T_{2}=d_{2} / v
\end{aligned}
$$

where $d_{1}$ and $d_{2}$ are the propagation distances for the direct and second path, respectively. These distances can be expressed as:

$$
\begin{aligned}
& d_{1}^{2}=(2 D)^{2}+s^{2} \\
& d_{2}^{2}=(4 D)^{2}+s^{2}
\end{aligned}
$$

where $D$ is the snowpack depth, $s$ is the horizontal distance between the transmitter and receiver. Substituting (4) and (5) into (2) and (3):

$$
\begin{aligned}
& T_{1}^{2}=\left((2 D)^{2}+s^{2}\right) / v^{2} \\
& T_{2}^{2}=\left((4 D)^{2}+s^{2}\right) / v^{2}
\end{aligned}
$$

Then, for dry snow, a well-known approximated relationship between the wave speed and the dielectric constant $\varepsilon$ of the medium can be used [29]:

$$
v \sim c / \sqrt{ } \varepsilon^{\prime}
$$

where $c$ is the speed of light. This way, manipulating (6), (7), and (8), it is possible to solve the mathematical system for the snowpack depth $D$, the wave speed in the medium $v$, and the dielectric constant $\varepsilon$ :

$$
\begin{gathered}
D^{2}=s^{2}\left(T_{1}^{2}-T_{2}^{2}\right) / 4\left(T_{2}^{2}-4 T_{1}^{2}\right) \\
v^{2}=3 s^{2} /\left(4 T_{1}^{2}-T_{2}^{2}\right) \\
\varepsilon^{\prime}=c^{2}\left(4 T_{1}^{2}-T_{2}^{2}\right) / 3 s^{2}
\end{gathered}
$$

Finally, for dry snow, a simultaneous estimate of $D$ and $\rho$ is achieved, given that between $\varepsilon$ and $\rho$ holds [29]:

$$
\varepsilon^{\prime}=1+1.8310^{-3} \rho
$$

where $\rho$ is measured in $\mathrm{kg} / \mathrm{m}^{3}$.

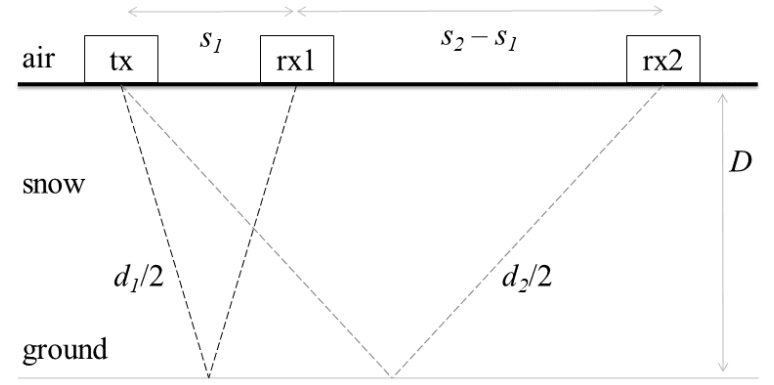

(a)

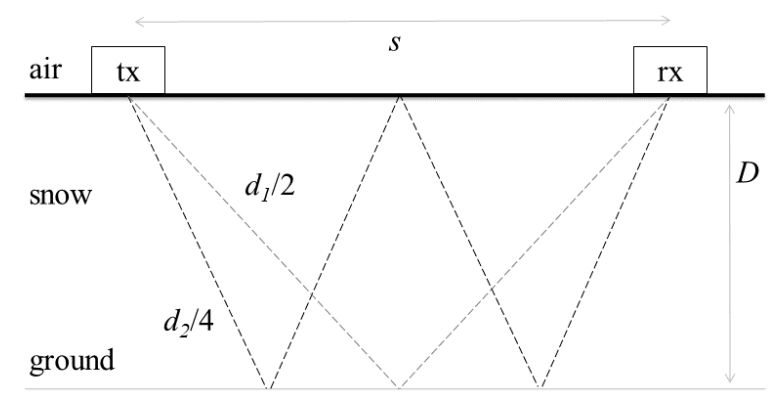

(b)

Fig. 1. Schema of the radar architecture: (a) dual-receiver implementation presented in [28]; (b) proposed multipath implementation. 


\section{EXPERIMENTAL SETUP AND RESULTS}

For the demonstration of the working principle of the multipath architecture, the transmitter and the receiver operate according to a stepped frequency modulated continuous wave (FMCW) configuration. The central frequency $f_{0}$ and bandwidth $B$ are $2.75 \mathrm{GHz}$ and $1.5 \mathrm{GHz}$ (from $2.0 \mathrm{GHz}$ to 3.5 $\mathrm{GHz}$ ), respectively. The radiators are open-ended WR340 waveguides, working on the fundamental $\mathrm{TE}_{10}$ mode. $\mathrm{S}$ band has been selected for an optimum compromise between penetration depth on dry snow, and achievable resolution.

The measurement set-up was composed by two open-ended WR340 waveguides acting as antennas, one used as transmitter while the other used as receiver. The latter is placed at two different distances $s$ (either $30 \mathrm{~cm}$ or $70 \mathrm{~cm}$ ) from the transmitting antenna, to study the response of the system with two different configurations. A metal rail was used both for supporting the antennas. This allows for selecting distances $s$ for the antennas from $20 \mathrm{~cm}$ to $100 \mathrm{~cm}$. Therefore, the two values selected for the demonstration of the proposed approach $(30 \mathrm{~cm}$ and $70 \mathrm{~cm}$ ) exemplify the achievable results for short and long separation between the transmitter and the receiver. In particular, it is expected that better results can be achieved for longer separations [30].

A portable Vector Network Analyzer (VNA), from Keysight (FieldFox N9916A), was used for generating the microwave signal and a portable PC was used for processing the received signal (Fig. 2). The processing consisted on performing the Inverse Fast Fourier Transform to the received signal applying a Nuttall window for reducing sidelobes.

\section{A. Field campaigns and experimental setup}

Two field campaigns have been performed for testing the system on real snowpack data. The first campaign (C1) was developed near to the village of Pila (Aosta) in the Italian Alps $\left(45^{\circ} 40^{\prime} 10^{\prime \prime} \mathrm{N} 7^{\circ} 18^{\prime} 30^{\prime \prime} \mathrm{E}\right)$. The campaign started the $4^{\text {th }}$ of February, ending the $8^{\text {th }}$ of February, both in 2019 and was performed at an altitude of around $2500 \mathrm{~m}$ above sea level (a.s.1.) in a shadow place with no inclination. During the whole campaign the snow conditions were dry. The number of measurements done was 5 . The second campaign $(\mathrm{C} 2)$ was developed close to the facilities of the Finnish Meteorological Institute (FMI) in Sodankylä, Finland (67'22'00" N 26 39'05" E) at an altitude of $179 \mathrm{~m}$ a.s.l. This campaign started the $18^{\text {th }}$ of March and ended the $12^{\text {th }}$ of April, in 2019. During the entire set of measurement used to validate the approach presented in this paper, the snowpack was dry. The number of measurements done was 37.

The radar measurements were compared with manual measurements on the field, performing each time a snowpit. During the $\mathrm{C} 1$, all the manual measurements were done with a density cutter of $198 \mathrm{~cm}^{3}$ and the density was measured with a vertical resolution of $10 \mathrm{~cm}$, averaging all the measurements for obtaining the bulk density and the SWE. During the C2, a set of measurements (C2_1) were validated with the same density cutter of $\mathrm{C} 1$, while another set of measurements (C2_2) were done around $30 \mathrm{~m}$ away from $\mathrm{C} 2$ 1 and were validated using a SWE tube provided by FMI [31]. In any case, for all campaigns, as manual measurements are destructive, the precise site for each snowpit is slightly moved sideway with respect to the previous one.

Before each manual measurement, directly above the site where the snowpit is planned to be realized, radar measurements (in most case, six) were done, averaging the collected data for producing the final result, in accordance with standard radar processing for fixed targets (as it is for snowpacks during the few seconds required), where multiple rapid measurements are used to enhance the equivalent signalto-noise ratio.

A radar trace was recorded both for $s=30 \mathrm{~cm}$ and $s=70 \mathrm{~cm}$. For each trace, the first (direct path) and the second (multipath) snow-ground echo were identified. An example of a trace for the receiver placed at $70 \mathrm{~cm}$ from the transmitter is shown in Fig. 3. To improve the identification of the second echo from the ground, a possible zone where this second echo should be, is calculated. In particular, after measuring the time of flight for the first echo, and taking into account the geometry of the problem and the possible values for the dielectric constant of dry snow (ranging from 1 to 2), the possible zone can be delimited (gray area in Fig. 3). It is worth noting that in some cases the identification of the second echo can be misled by a weak snow-ground reflection, or vice-versa by a strong reflection within the snowpack (e.g., due to an icy layer). In these cases, the collected data is discarded, and the radar measurement repeated.

\section{B. Results and discussion}

Results for the C1, C2_1 and $\mathrm{C} 2 \_2$ are shown in Fig. 4, Fig. 5 and Fig. 6, respectively. In particular, in all cases the real value (ground truth) for the snowpack depth $D$ and SWE, measured with the manual analysis, is compared with the radar measurements for $s=30 \mathrm{~cm}$ and $s=70 \mathrm{~cm}$.

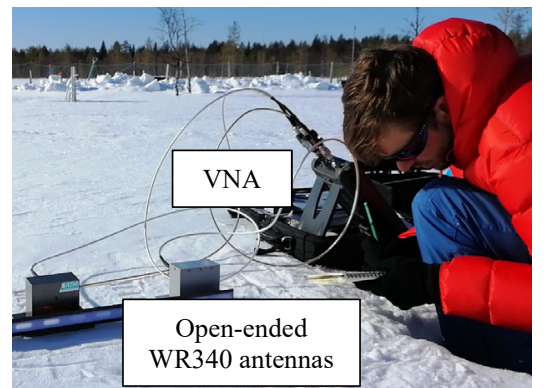

Fig. 2. Photograph of the measurement setup during the second campaign $\mathrm{C} 2$.

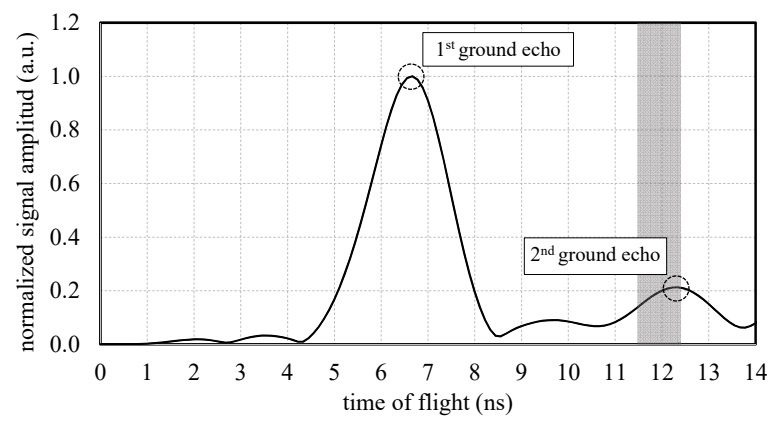

Fig. 3. Example of a radar trace. First and second ground echoes are identified with a circle. The possible zone is indicated with a grey shadow. 
In all cases, solid and dashed lines represent the snow depth $D$ and SWE, respectively, measured with the manual analysis, while dots and crosses represent the snow depth $D$ and SWE, measured with the proposed radar approach for $s=30 \mathrm{~cm}$ and $s$ $=70 \mathrm{~cm}$, respectively. The comparison is done for several different measurements, covering a temporal evolution of the snowpack of several days.

In particular, for $\mathrm{C} 1$ and $\mathrm{C} 2 \_1$ a manual measurement per day was done, resulting in a time series of five and nine days for $\mathrm{C} 1$ and $\mathrm{C} 2 \_1$, respectively. For C2_2, in some cases two manual measurements per day were done, resulting in a time series spanning 21 days. For the longer campaigns, C2_1 and C2 2, where the effect of the time evolution of the snowpack is naturally more evident, the radar measurements were able to track the expected behavior (known as packing of the snowpack). In particular, the snowpack depth $D$ tends to get smaller, while the SWE tends to remain constant because of the gradual increase for the snowpack density.

Overall, the results are summarized graphically in Fig. 7 and in terms of root mean square error (RMSE) and mean absolute error (MAE) in Table I. As anticipated, it can be appreciated that on average the radar measurements are better for a larger antenna separation $\mathrm{s}$. This is due to a larger difference in the propagation distance between the direct and second path, which reduces the correlation between the two measurements, hence improving the results when solving the mathematical problem. For $\mathrm{s}=70 \mathrm{~cm}$, a MAE of $4.7 \mathrm{~cm}$ and $3.6 \mathrm{~cm}$ is achieved for the snowpack depth D and SWE, respectively. In addition, the results are grouped around the diagonal line in Fig. 7, thus showing no significant bias. In relative terms, the achieved MAE implies a relative error of around $5 \%$ and $20 \%$ for the snowpack depth D and SWE, respectively. The larger dispersion for the SWE is mostly due to the fact that it is calculated as the combination of two independent parameters, depth $D$ and density $\rho$, as shown in (1). Therefore, the two independent uncertainties contribute, statistically, to enlarge the dispersion for the SWE.

\section{CONCLUSION}

This paper presented a radar technique able to calculate the snowpack depth, density, and SWE, particularly suited for portable radars. The proposed technique is based on multipath propagation, and it is completely self-standing (e.g., it does not required assumption on the snowpack density, external devices, complex antenna movements, and/or post-processing inverse techniques). It was experimentally validated against manual snowpits during three field campaigns with dry snow, showing a mean absolute error better than $5 \mathrm{~cm}$ for both depth and SWE.

According to the application, this error can be improved, for example working with an antenna separation larger than $70 \mathrm{~cm}$, and this can be of interest for monitoring specific sites, for example for validating satellite data. On the other hand, if the radar is used to sample at many different places an entire mountain catchment, for example for water resource management, where errors are expected to be averaged out, smaller antenna separations can be used to improve the compactness and portability.
TABLE I

ROOT MEAN SQUARE ERROR (RMSE, LEFT) AND MEAN ABSOLUTE ERROR (MAE, RIGHT) FOR THE RADAR MEASUREMENT FOR THE DIFFERENT CAMPAIGNS. ALL VALUES IN CM

\begin{tabular}{ccccc}
\hline \hline Campaign & $\begin{array}{c}\text { Snowpack } \\
\text { depth } D \\
s=30 \mathrm{~cm}\end{array}$ & $\begin{array}{c}\text { Snowpack } \\
\text { depth D } \\
s=70 \mathrm{~cm}\end{array}$ & $\begin{array}{c}\text { Snowpack } \\
\text { SWE } \\
s=30 \mathrm{~cm}\end{array}$ & $\begin{array}{c}\text { Snowpack } \\
\text { SWE } \\
s=70 \mathrm{~cm}\end{array}$ \\
\hline C1 & $4.9 / 4.3$ & $6.7 / 6.1$ & $10.7 / 7.3$ & $3.4 / 2.9$ \\
C2_1 & $8.2 / 7.4$ & $4.6 / 3.8$ & $11.1 / 9.5$ & $3.4 / 2.8$ \\
C2_2 & $8.1 / 6.6$ & $6.5 / 4.7$ & $5.8 / 4.7$ & $5.3 / 4.1$ \\
TOTAL & $7.6 / 6.4$ & $6.1 / 4.7$ & $9.1 / 7.0$ & $4.7 / 3.6$ \\
\hline \hline
\end{tabular}

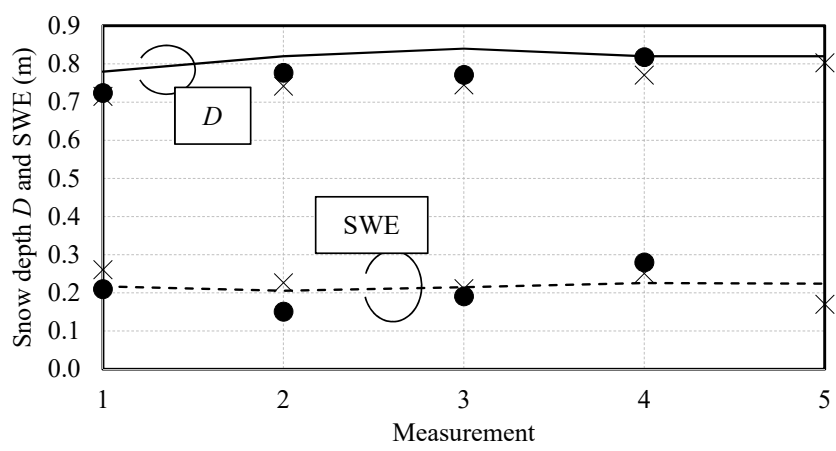

Fig. 4. Results for the snowpack depth $D$ and SWE for the experimental campaign $\mathrm{C} 1$. Dots and crosses indicate results related to the radar measurement with $s=30 \mathrm{~cm}$ and $s=70 \mathrm{~cm}$, respectively. Solid and dashed line indicates the ground truth for $D$ and $\mathrm{SWE}$, respectively.

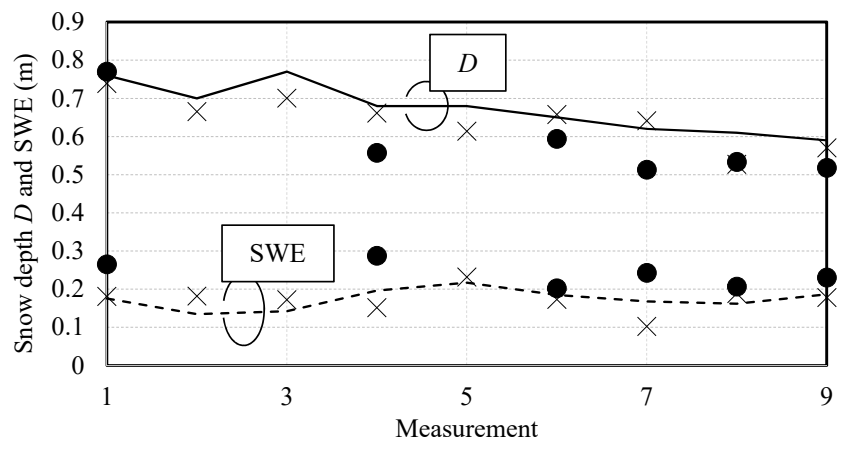

Fig. 5. Results for the snowpack depth $D$ and SWE for the experimental campaign $\mathrm{C} 2$ 1. Dots and crosses indicate results related to the radar measurement with $s=30 \mathrm{~cm}$ and $s=70 \mathrm{~cm}$, respectively. Solid and dashed line indicates the ground truth for $D$ and SWE, respectively.

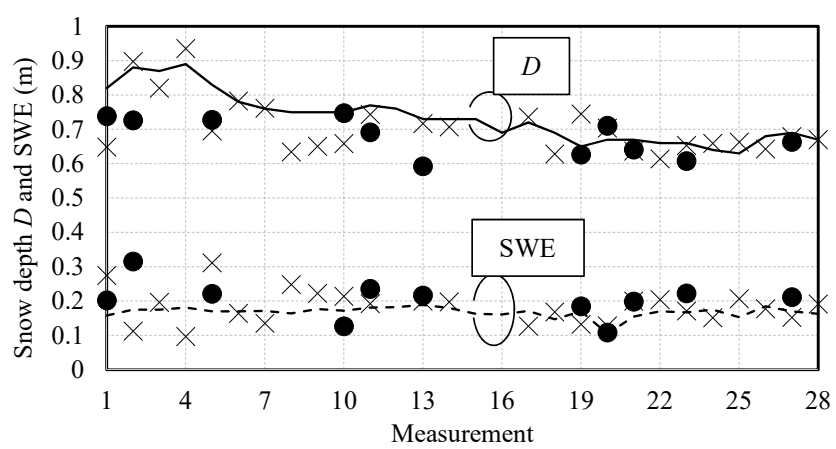

Fig. 6. Results for the snowpack depth $D$ and SWE for the experimental campaign $\mathrm{C}_{2} 2$ 2. Dots and crosses indicate results related to the radar measurement with $s=30 \mathrm{~cm}$ and $s=70 \mathrm{~cm}$, respectively. Solid and dashed line indicates the ground truth for $D$ and SWE, respectively. 


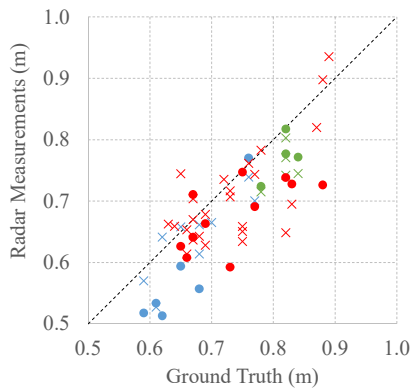

(a)

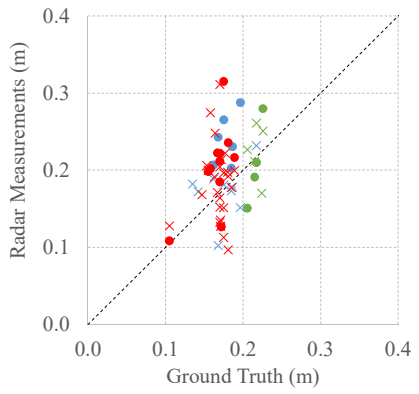

(b)
Fig. 7. Summary of all the radar measurements versus the corresponding ground truth for the: (a) snowpack depth $D$; (b) SWE. Dots and crosses indicate results related to the radar measurement with $s=30 \mathrm{~cm}$ and $s=70 \mathrm{~cm}$, respectively. Green represents results from $\mathrm{C} 1$, blue indicates results from $\mathrm{C} 2 \_1$ and red shows results from $\mathrm{C} 22$.

\section{ACKNOWLEDGMENT}

The authors would like to thank Regione Valle d'Aosta, Fondazione Montagna Sicura, Centro Addestramento Alpino of the Italian Army, the Finnish Meteorological Institute, and the project SnowAPP (funded by the Academy of Finland), for their support during the experimental campaigns.

\section{REFERENCES}

[1] D. G. Vaughan, et al., Observations: Cryosphere, in Climate change 2013: The physical science basis, Cambridge University Press, Cambridge, United Kingdom, 2013.

[2] D. Viviroli, et al., "Climate change and mountain water resources: overview and recommendations for research, management and policy," Hydrology and Earth System Sciences, vol. 15, pp. 471-504, 2011.

[3] M. C. Serreze et al., "Characteristics of the western United States snowpack from snowpack telemetry (SNOTEL) data," Water Resour Res, vol. 35, pp. 2145-2160, July 1999.

[4] S. A. Malek, S. D. Glaser, and R. C. Bales, "Wireless sensor networks for improved snow water equivalent and runoff estimates," IEEE Access, DOI 10.1109/ACCESS.2019.2895397, 2019.

[5] N. Rodriguez-Alvarez et al., "Snow thickness monitoring using GNSS measurements," IEEE Geosci. Remote Sens. Lett., vol. 9, no. 6, pp. 1109 1113, Nov. 2012..

[6] P. Henkel et al., "Snow water equivalent of dry snow derived from GNSS carrier phases," IEEE Trans. Geosci. Remote Sens., vol. 56, no. 6, pp. 3561-3572, June 2018.

[7] J. Guo et al., "Mapping the spatial distribution and time evolution of snow water equivalent with passive microwave measurements," IEEE Trans. Geosci. Remote Sens., vol. 41, no. 3, pp. 612-621, March 2003.

[8] L. Jiang et al., "Estimation of snow water equivalence using the polarimetric scanning radiometer from the cold land processes experiments (CLPX03)," IEEE Geosci. Remote Sens. Lett., vol. 8, no. 2, pp. 359-363, March 2011.

[9] J. Shi, J. Dozier, and H. Rott, "Snow mapping in alpine regions with synthetic aperture radar," IEEE Trans. Geosci. Remote Sens., vol. 32, no. 1, pp. 152-158, Jan. 1994.

[10] G. Engen, T. Guneriussen, and Ø. Overrein, "Delta-K interferometric SAR technique for snow water equivalent (SWE) retrieval," IEEE Geosci. Remote Sens. Lett., vol. 1, no. 2, pp. 57-61, April 2004.

[11] S. Pettinato et al., "The potential of COSMO-SkyMed SAR images in momitoring snow cover characteristics," IEEE Geosci. Remote Sens. Lett., vol. 10, no. 1, pp. 9-13, Jan. 2013.

[12] C. Xiong and J. Shi, "The potential for estimating snow depth with QuikScat data and a snow physical model," IEEE Geosci. Remote Sens. Lett., vol. 14, no. 7, pp. 1156-1160, July 2017.
[13] J. Zhu et al., "Forward and inverse radar modeling of terrestrial snow using SnowSAR data," IEEE Trans. Geosci. Remote Sens., vol. 56, no. 12, pp. 7122-7132, Dec. 2018.

[14] R. Shah et al., "Remote sensing of snow water equivalent using P-band coherent reflection," IEEE Geosci. Remote Sens. Lett., vol. 14, no. 3, pp. 309-313, March 2017.

[15] L. L. Wilson, L. Tsang, J.-N. Hwang, and C.-T. Chen, "Mapping snow water equivalent by combining a spatially distributed snow hydrology model with passive microwave remote-sensing data," IEEE Trans. Geosci. Remote Sens., vol. 37, no. 2, pp. 690-704, March 1999.

[16] C. Derksen, A. E. Walker, B. E. Goodison, and J. W. Strapp, "Integrating in situ and multiscale passive microwave data for estimation of subgrid scale snow water equivalent distribution and variability," IEEE Trans. Geosci. Remote Sens., vol. 43, no. 5, pp. 960-972, May 2005.

[17] M. P. Clark et al., "Assimilation of snow covered area information into hydrologic and land-surface models," Adv. Water Resour., vol. 29, no. 8, pp. 1209-1221, 2006.

[18] Y. Yamaguchi, M. Mitsumoto, M. Sengoku, and T. Abe, "Synthetic aperture FM-CW radar applied to the detection of objects buried in snowpack," IEEE Trans. Geosci. Remote Sens., vol. 32, no. 1, pp. 1118, Jan. 1994.

[19] J. Holmgren, M. Sturm, N. E. Yankielun, and G. Koh, "Extensive measurements of snow depth using FM-CW radar," Cold Reg Sci Technol, vol. 27, no. 1, pp. 17-30, Jan. 1998.

[20] J. H. Bradford, J. T. Harper, and J. Brown, "Complex dielectric permittivity measurements from ground-penetrating radar data to estimate snow liquid water content in the pendular regime," Water Resour Res, vol. 45, no. 8, pp. 1-12, Aug. 2009.

[21] A. Heilig, O. Eisen, and M. Schneebeli "Temporal observations of a seasonal snowpack using upward-looking GPR," Hydrol. Process., vol. 24, no. 22, pp. 3133-3145, Oct. 2010.

[22] K. Morrison, and J. Bennett, "Tomographic profiling-A technique for multi-incidence-angle retrieval of the vertical SAR backscattering profiles of biogeophysical targets", IEEE Trans. Geosci. Remote Sens., vol. 52, no. 2, pp. 1350-1355, Feb. 2014.

[23] L. Schmid et al., "A novel sensor combination (upGPR-GPS) to continuously and nondestructively derive snow cover properties," Geophys. Res. Lett., vol. 42, no. 9, pp. 3397-3405, Sept. 2015.

[24] L. Schmid, J. Schweizer, J. Bradford, and H. Maurer, "A synthetic study to assess the applicability of full-waveform inversion to infer snow stratigraphy from upward-looking ground-penetrating radar data," Geophysics, vol. 81, no. 1, pp. WA213-WA223, 2016.

[25] J. S. Clair and W. S. Holbrook, "Measuring snow water equivalent from common-offset GPR records through migration velocity analysis," The Cryosphere, vol. 11, pp. 2997-3009, 2017.

[26] N. Griessinger, F. Mohr, and T. Jonas, "Measuring snow ablation rates in alpine terrain with a mobile multioffset ground-penetrating radar system," Hydrol. Process., vol. 32, no. 21, pp. 3272-3282, Oct. 2018.

[27] R. Persico, Ground Penetrating Radar, Wiley, Hoboken, New Jersey, U.S.A., 2014.

[28] M. Pasian, M. Barbolini, F. Dell'Acqua, P. F. Espín-López, and L. Silvestri, "Snowpack Monitoring Using a Dual-Receiver Radar Architecture," IEEE Trans. Geosci. Remote Sens., Vol. 57, No. 2, pp. 1195-1204, Feb. 2019

[29] M. T. Hallikainen, F. Ulaby, and M. Abdelrazik, "Dielectric properties of snow in the 3 to $37 \mathrm{GHz}$ range," IEEE Trans. Antennas Propag., vol. 34, no. 11, pp. 1329-1340, Nov. 1986.

[30] P. F. Espin-Lopez, M. Pasian, M. Barbolini, and F. Dell'Acqua, "Optimization of a multi-receiver FMCW radar for snow cover monitoring," $12^{\text {th }}$ European Conference on Antennas and Propagation (EuCAP 2018), London, UK, April 9-13, 2018.

[31] N. J. Kinar and J. W. Pomeroy, "Measurement of the physical properties of the snowpack," Review of Geophysics, vol. 53, pp. 1-64, 2015. 